\title{
OFDI Reverse Technology Spillovers of Western China
}

\author{
Xianping Yuan, Yuanyuan Zhang* \\ School of Xi'an University of Science and Technology, Xi'an, China \\ Email: *zyy15091373521@sina.com
}

How to cite this paper: Yuan, X.P. and Zhang, Y.Y. (2018) OFDI Reverse Technology Spillovers of Western China. Open Journal of Social Sciences, 6, 62-70. https://doi.org/10.4236/jss.2018.62006

Received: January 12, 2018

Accepted: February 6, 2018

Published: February 9, 2018

Copyright $\odot 2018$ by authors and Scientific Research Publishing Inc. This work is licensed under the Creative Commons Attribution International License (CC BY 4.0).

http://creativecommons.org/licenses/by/4.0/

\begin{abstract}
As an important technology spillover path, FDI plays an increasingly important role in promoting domestic technological progress and optimizing industrial structure. This paper selects the data of GDP, R\&D investment and fixed assets investment and employment in China from 2004 to 2011, and adopts a simple and classical linear-model to investigate the relationship between to increase the risk. From the regression results (t-statistics and p-value), there is the effect of reverse technology spillovers in Western China. And China in western region has the problems that economy and science and technology are underdeveloped, so the western region through the increase of foreign direct investment to promote technological upgrading is very necessary. At the same time, we believe that the government of the western region can improve and enhance the technical level, through foreign direct investment, so as to promote local economic development; at the same time, the western region enterprises through overseas investment, especially in technology intensive industry investment to improve the technical level, and mergers and acquisitions may be the effective way to obtain such a spillover effect.
\end{abstract}

\section{Keywords}

OFDI, Reverse Technology Spillovers, Western China

\section{Introduction}

\subsection{Background}

\subsubsection{Global Perspective}

Outward Foreign Direct Investment (OFDI) is a vital channel of International technology spillovers, since Endogenous Growth Theory has been proposed. Technology improvement of one country can rely on the domestic development capital. At the same time, it can also be obtained from other countries' develop- 
ment capital through trade, namely FDI and OFDI. Not only can foreign investment of developed countries obtain technology spillovers from host countries, but also the foreign investment from emerging countries gradually becomes a significant channel to get foreign advanced technology so as to improve domestic productivity and technology.

Most of the former researches focused on the FDI technology spillovers for host countries and reverse technology spillovers between developed countries. On the contrary, the effects of OFDI on parent companies and home countries were ignored previously. Knowledge spillovers have been a motive of emerging countries' OFDI. Some MNEs can promote its technology and productivity through investing abroad and some transmission mechanisms.

\subsubsection{China Perspective}

China is the biggest developing country. For our country as an emerging economy, foreign investment and trade acts as an important channel of technology progress. In the aspect of foreign investment, China has gradually been transforming from absorbing foreign investment to cross-bordered investment in recent years. According to the statistics of Commerce Department, Chinese outward FDI flow increased from $\$ 2.85$ billion to $\$ 56.53$ billion from 2003 to 2009 . Under the circumstance, it has been the research focus of this field. Chinese government has enacted the policy of "going out", which has accelerated the research of relevant aspect. One of expectation of this strategy is to promote industrial upgrading and technology progress. Researchers focus on the technology effect of China's outward foreign direct investment.

Western China is less developed compared to eastern China. It will be more important or favorable for the development of this region to increase OFDI in the perspective of technology spillovers. In other words, this region can escalate through increasing outward foreign direct investment to other more developed countries and regions.

\subsection{Research Purposes}

Whether fast-growing outward foreign direct investment accelerates China's technological progress and whether China obtains reverse technology spillovers from investing host countries have been the crucial questions, especially in western China.

Therefore, this research proposal has two purposes. The first one is to prove the existence of reverse technology spillovers of OFDI in western China. Secondly, it probes into what implications and suggestions should be afforded for local government of this region if this kind of spillovers exists.

\section{Literature Review}

\subsection{Proposition of Assumption}

Kogut and Chang (1991) [1] took Japan's OFDI to the United States as empirical 
object and proved that Japan's direct investment to the United States are mainly distributed in R\&D intensive industries, which favors the pattern of Joint Venture. Then he proposed the guess of reverse technology spillovers. It was the first research on OFDI's technology spillovers to home countries.

Neven and Siotis (1996) [2] adopted the similar method to examine the effect among European countries and also held that FDI can generate technology spillovers to home countries as well as host countries.

\subsection{Introduction of Model}

The introduction of model is based on the FDI R\&D spillovers model. Coe and Helpman (1995) [3] proposed the "C-H" model to test FDI technology spillovers. Potterie and Lichtenberg (2001) [4] introduced OFDI as a spillover channel into the "C-H" model to test OFDI technology spillovers. They improved and completed the international R\&D technology spillover regression model and used Total Factor Productivity (TFP) to measure technology level of home countries. They took use of 13 countries' data, including America, Japan and so on, to examine international R\&D spillovers of three channels (trade, FDI and OFDI). It turned out investment to R\&D-intensive countries improved productivity of home countries significantly. That suggested OFDI has a similar impact or function in R\&D spillovers with trade and FDI.

\subsection{Technology Improvement}

Research results of the effect of OFDI on technology are different. There are two different kinds of results: the OFDI can promote technology progress significantly and on the contrary, OFDI doesn't have a positive impact on technology improvement of home countries.

Some researchers actually proved the statistically significantly positive influence of OFDI on domestic technology level. Fosfuri and Motta (1999) [5] validated companies in technology-behind countries can get technical promotion through investing to technology-advanced countries. Parent companies can promote native productivity and technology level by demonstration-simulation effect, labor-training effect and so on, which theoretically supported the thesis that OFDI can promote technology progress of own countries. Branstetter (2000) [6] proved Japan's direct investment to the United States indeed improved the technology level of firms. Fosfuri and Motta (2001) [7] evidenced that technology-intensive firms can get unique technology of host countries through OFDI and achieve escalation. Pradhan and Singh (2008) [8] researched FDI of Indian automotive industry. The result showed that regardless of investing to developed countries or emerging countries, Indian automobile industry achieved significant reverse technology spillovers effect. Li Rui (2003) [9] thought MNEs could get important technology through M\&A-one pattern of OFDI. Du Qunyang and Zhu Qin (2004) [10] defined this kind of OFDI as technology-seeking OFDI, which was aimed at obtaining information, intelli- 
gence and development institutions of host countries to raise its own competitiveness. Ru Yucong (2004) [11] investigated the effect of OFDI on the economy of home countries on technology-seeking motivation of MNEs. Zhao Wei, Gu Guangdong and He Yuanqing (2006) [12] proposed R\&D transmission mechanisms and models suitable for China on the basis of foreign articles. They tried to examine the relationship between OFDI and China's technology progress and found that China's OFDI has significant reverse technology spillovers, especially the investment to $\mathrm{R} \& \mathrm{D}$-intensive countries and regions. Zhao Jiaying and $\mathrm{Fu}$ Yuanzhai (2009) [13] held that OFDI reverse technology spillovers include firm level, industrial level and country level. These three level spillovers happen in sequence of firm, industry and country, in which the firm level is the core aspect. Guo Fei and Huang Ya (2012) [14] built a triangle loop transmission model including technical interaction, technical transmission and technology absorption. They believed that Huawei obtained OFDI reverse technological spillovers successfully.

However, there are also some opposite research results. Bitzer and Kerekes (2008) [15] introduced the industry-level data of OECD 17 countries to test OFDI reverse spillovers and discovered OFDI had a negative impact on Total Factor Productivity (TFP), which was diversified among different countries. Dierk Herzer (2010) [16] also proved the existence of national differences of reverse technology spillovers through researching 33 developing countries' Outward Foreign Direct Investment. Wang Ying and Liu Sicong (2008) [17] applied the International R\&D spillover regression framework to empirically analyzing the impact of many channels on China's technology advance but their result indicated OFDI didn't have a stimulating effect on China's technology improvement.

\section{Methodology}

\subsection{Data Sources}

To reach research objectives, I collect data from "China Statistical Yearbook", "China's foreign direct investment statistical bulletin", "China's major science and technology indicators database" and "OECD Factbook".

I use the 8-year data of China's OFDI stock, GDP, R\&D stock and fixed assets investment and employment figure from 2004 to 2011. GDP, fixed assets investment and employment figure to calculate TFP (Total Factor Productivity) to evaluate China's technology improvement level. Finally I build a time-series regression model to examine reverse spillover's existence through learning and consulting other researches.

I adopt the criteria of "China's foreign direct investment statistical bulletin" to classify western region. Western China should include 12 provinces and cities: Inner Mongolia, Guangxi, Sichuan, Chongqing, Guizhou, Yunnan, Tibet, Shaanxi, Gansu, Qinghai, Ningxia, Xinjiang, according to this standard.

These are regional data I used in this research proposal. TFP is a relative 
number and it is calculated by formula. OFDI stock, R\&D stock and GDP are measured in 100 million. I use year-data to run regression because I think technological spillover is a long-term result rather than a short-term and it's not very reasonable to use month-data or quarter-data to analyze.

Because Chinese OFDI stock statistics are only from 2004, so I can just collect data and analyze from the year of 2004, as shown in Table 1. In addition, I didn't obtain the data of R\&D after 2011 due to the incomplete statistic, so I can just run regression from 2004 to 2011 . Although the time period is not very long and the sample size is not large, the availability of data is limited.

\subsection{Variables}

For this research proposal, I introduce three variables: TFP, OFDI and R\&D/GDP. My purpose is to find the relationship between the dependent variable-TFP and independent one-OFDI to explain the reverse technology spillovers.

TFP refers to Total Factor Productive, normally called rate of technological progress. Its definition is the part that output growth rate exceeds input growth rate. It is the symbol of technology improvement. This variable is usually used to measure technological level of home country. I take it as the dependent variable in my regression model. The value of TFP cannot get directly and I can just calculate it through some method indirectly. There is a common method called Production Function Method, which is a popular method in the research and come from its definition. The computational formula is as followed:

$$
\ln \mathrm{TFP}_{t}=\alpha_{0}+\alpha_{1}\left(\mathrm{RD}_{t}^{d} / \mathrm{GDP}_{t}\right)+\alpha_{2} \ln \mathrm{OFDI}_{t}+\varepsilon_{t}
$$

In this equation, Y refers to output. I use GDP from China Statistical Yearbook to represent it. $K$ is capital stock and fixed assets investment is used to calculate it. $L$ is labor input and I collect the data of total employment figure of western China from China Statistical Yearbook to calculate. In the progress of calculation, there is another problem that the value of $\alpha$ and $\beta$. They are separately labor output elasticity and capital output elasticity. To calculate easily, I make $\alpha, \beta=0.5$ through consulting other references.

OFDI is the value of outward foreign direct investment of western China. It is an independent variable in my regression model. I will examine the relationship between OFDI and TFP by running regression. If OFDI has a significant impact on TFP, there is some relationship between these two variables, which is the purpose of this research proposal.

Table 1. 2004-2011 years Chinese OFDI stock statistics.

\begin{tabular}{cccccccccc}
\hline & 2004 & 2005 & 2006 & 2007 & 2008 & 2009 & 2010 & 2011 \\
\hline TFP & 0.5534 & 0.5822 & 0.6275 & 0.6860 & 0.7582 & 0.9032 & 0.9291 & 0.9217 \\
OFDI & 15.02 & 35.83 & 53.56 & 135.28 & 207.38 & 290.14 & 439.15 & 596.58 \\
R\&D & 252.85 & 312.13 & 357.49 & 441.38 & 540.83 & 724.87 & 874.27 & 1040.97 \\
GDP & 28603.43 & 33590.29 & 39525.51 & 47865.72 & 58256.57 & 66973.48 & 81408.45 & 91234.96 \\
\hline
\end{tabular}


$R \& D$ refers to $R \& D$ investing capital of western China. $R \& D$ input will contribute to technological improvement, so it's a case leading to TFP growth. Researchers often use R\&D/GDP in their analyses. It's a relative number also and explains the proportion of $R \& D$ in GDP. It's another independent variable. OFDI and domestic R\&D capital can both influence TFP. I can examine whether this two channel can have a same impact on TFP through some tests.

\subsection{Model}

Through analyzing the research purpose and leaning others' researches, I use a simple and classical linear-model to investigate the relationship between TFP and OFDI. The model is:

$$
\ln \mathrm{TFP}_{t}=\alpha_{0}+\alpha_{1}\left(\mathrm{RD}_{t}^{d} / \mathrm{GDP}_{t}\right)+\alpha_{2} \ln \mathrm{OFDI}_{t}+\varepsilon_{t}
$$

In this Equation, (1) $\mathrm{TFP}_{t}$ indicates TFP in the end of year $t$, (2) $\mathrm{OFDI}_{t}$ indicates OFDI amount in the end of year $t$ and (3) $\mathrm{RD}_{t}^{d}$ indicates $\mathrm{R} \& \mathrm{D}$ expenditure in the end of year $\mathrm{t}$. In the regression, I will use $\mathrm{Y}, \mathrm{X} 1$ and $\mathrm{X} 2$ to represent $\mathrm{TFP}_{t}$, $\mathrm{OFDI}_{t}$ and $\mathrm{RD}_{t}^{d} / \mathrm{GDP}_{t}$.

In this model, $\alpha_{0}$ is the intercept, $\alpha_{1}$ and $\alpha_{2}$ are coefficients and indicates the impact of two independent variables on $\ln$ TFP. My purpose is to use $\alpha_{1}$ and $\alpha_{2}$ to find out the relationship between dependent and independent variables. Finally, I will examine the existence of reverse technological spillovers in western China of OFDI through t-test.

\section{Regression and Discussion}

\subsection{Graph-Scatter}

In this empirical part, I use the statistical software-Eviews to run regression. Before running regression, I draw the scatter to find out some basic relationship obviously.

It can be seen from Figure 1 that $\mathrm{Y}, \mathrm{X} 1$ and $\mathrm{X} 2$ have a similar increasingly changing trend. Because X2-OFDI is an absolute number but $\mathrm{Y}$ and $\mathrm{X} 1$ represent relative numbers, so I take the natural logarithm on X2.

\subsection{Regression Result}

I use Eviews to do this regression. As a result, see Figure 2.

Regression result: $\ln Y=-1.527740+67.31083 X 1+0.114566 \ln X 2$

First, R-squared is 0.964011 and Adjusted R-squared is 0.949615 which indicate this model is suitable for this analysis. Its fitting degree is high.

From the regression result above, we can see $\ln \mathrm{X} 2$ has significantly positive effect on $\ln Y$ (t-statistic $=4.421644$ and $\mathrm{p}$-value $=0.0069$ ). OFDI has a significant impact on TFP. However, X1 is not very significant ( $\mathrm{t}$-statistic $=1.985191$ and $\mathrm{p}$-value $=0.1039$ ) but I think it is not reasonable because R\&D capital of one country can promote its technology progress, that is to say, when we use TFP to measure technical improvement, R\&D capital should have a significantly positive 


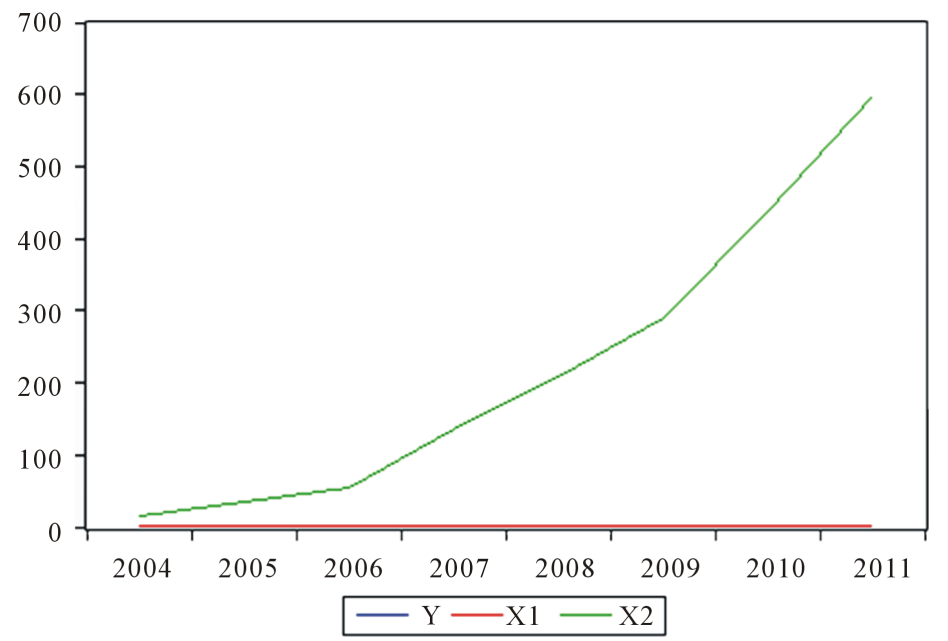

Figure 1. The scatter plot of the basic relation.

Dependent Variable: LNY

Method: Least Squares

Date: 04/28/15 Time: 14:53

Sample: 20042011

Included observations: 8

\begin{tabular}{lcccc}
\hline \hline \multicolumn{1}{c}{ Variable } & Coefficient & Std. Error & t-Statistic & Prob. \\
\hline \hline C & -1.527740 & 0.237197 & -6.440795 & 0.0013 \\
X1 & 67.31083 & 33.90647 & 1.985191 & 0.1039 \\
$\operatorname{lnX} 2$ & 0.114566 & 0.025910 & 4.421644 & 0.0069 \\
\hline \hline R-Squared & 0.964011 & Mean dependent var & -0.313650 \\
Adjusted R-squared & 0.949615 & S.D. dependent var & 0.211773 \\
S.E. of regression & 0.047536 & Akaike info criterion & -2.974674 \\
Sum squared resid & 0.011298 & Schwarz criterion & -2.944884 \\
Log likelihood & 14.89870 & Hannan-Quinn criter & -3.175600 \\
F-statistic & 66.96535 & Durbin-Watson STAT & 1.918593 \\
Prob (F-statistic) & 0.000246 & & & \\
\hline \hline
\end{tabular}

Figure 2. Regression results.

impact on TFP. The reason of this phenomenon maybe is the sample size and the calculation of TFP. But this can be solved by enlarging sample improve method of calculation. That is to say, OFDI and R\&D/GDP have positively impact on TFP. When OFDI increase $1 \%$, the TFP will increase $0.1146 \%$.

There are some mechanisms to generate reverse technology spillovers through OFDI channel. Labor mobility, demonstration and training can all generate spillovers. So, OFDI is actually a technological spillover channel. In western China, OFDI leads to the growth of Total Factor Productive and brings technical improvement of this region. There exist technology spillovers in western China.

\section{Conclusion and Implications}

\subsection{Existence}

From the regression results (t-statistics and p-value), it can be observed that OFDI is significantly related to the TFP and their relationship is also positive. 
Consequently, there is the effect of reverse technology spillovers in western China.

Western China is not very developed and its technology is not highly advanced as other developed regions. As can be seen from the initial research result, we can know it is favorable and necessary for western region to increase its OFDI to promote technical escalation.

\subsection{Suggestions}

The existence of OFDI reverse spillovers offers some implications for development of local region.

First and foremost, local government can improve and upgrade technology level through OFDI and thus can promote local economy.

Secondly, companies of western region can heighten their technology level by investing overseas especially for technology-intensive industry. M\&A may be an effective way to obtain this kind of spillovers.

Last but not least, China can increase OFDI to developed countries and regions which possess abundant R\&D factors, such as high-level technicians and core technology and so on.

\section{Limitations}

There are some limitations in this research proposal due to personal ability and time limitation.

To start with, the sample size used in this proposal is small, involving only 8 years from 2004 to 2011 due to the unavailability of other data. I could neither collect the data of OFDI before 2004 due to the incomplete statistics, nor obtain the data of R\&D from 2012 to 2014 from "China's major science and technology indicators database". As a result, the test and the regression seem inaccurate, for instance, the regression result that $\mathrm{X} 1$ is not quite significant but in theoretically domestic R\&D capital should have a significant impact on TFP.

Besides, regression model used in this essay is a basic one, which only includes two independent variables-OFDI and R\&D/GDP. Only two obvious indicators are considered to measure the relationship. The model is simple and it expresses the relation of OFDI and TFP directly rather than the foreign R\&D.

Apart from that, I think if the variable-foreign R\&D spillovers stock can be included in this model, it will be more complete and accurate to weight the impact of OFDI on technology level of home countries. But the truth is that it is difficult to calculate foreign R\&D spillovers stock for my ability, as it requires the international data and complex calculation.

Furthermore, I failed to take the industry factor into account. For technology-intensive industry, reverse technology spillovers of OFDI may be more obvious and easier to be measured. The total number of OFDI as a whole was taken to do research, instead of the divided industry. In the subsequent research, I will perhaps try the data of some different industries, run regression respectively and compare them to think about the different transmission mechanisms in different industries. 
Ultimately, the calculation of TFP is complicated. In spite of that my result is not as accurate to the value of $\alpha$ and $\beta$, I will study more references to make up for it.

\section{References}

[1] Kogut, B. and Chang, S. (1991) Technological Capabilities and Japanese Foreign Direct Investment in the United States. The Review of Economics and Statistics, 73, 401-413.

[2] Neven, D. and Siotis, G. (1996) Technology Sourcing and FDI in the EC: An Empirical Evaluation. International Journal of Industrial Organization, 14, 543-560.

[3] Coe, D. and Helpman, E. (1995) International R\&D Spillovers. European Economic Review, 39, 859-887.

[4] van Pottelsberghe, B. and Lichtenberg, F. (2001) Does Foreign Direct Investment Transfer Technology across Borders? The Review of Economics and Statistics, 83, 490-497.

[5] Andrea, F. and Massimo, M. (1999) Multinational without Advantages. Scandinavian Journal of Economic, 101, 617-630.

[6] Branstetter, L. (2000) Is Foreign Direct Investments a Channel of Knowledge Spillovers? Evidence from Japan's FDI in the United States. NBER Working Paper No. 8015.

[7] Fosfuri, A., Motta, M. and Ronde, T. (2001) Foreign Direct Investment and Spillovers through Workers' Mobility. Journal of International Economics, 53, 205-222.

[8] Pradhan, J.P. and Singh, N. (2009) Outward FDI and Knowledge Flows: A Study of the Indian Automotive Sector. International Journal of Institutions and Economies, $1,156-187$.

[9] Li, R. (2003) Analysis of the Motivation of Technology Seeking for Transnational Mergers and Acquisitions. World Economy, 2, 19-24.

[10] Du, Q.Y. and Zhu, Q. (2004) Theory and Practice of Chinese Enterprise Technology Acquisition Overseas Direct Investment. International Trade Problem, 11, 66-69.

[11] Ru, Y.C. (2004) Technology Seeking Foreign Direct Investment and Its Influence on the Home Economy. Economic Review, 2, 109-112.

[12] Zhao, W. and He, Y. (2006) Extroverted FDI and China's Technological Progress: Mechanism Analysis and Tentative Demonstration. Management World, 7, 53-60.

[13] Zhao, J. and Fuyuan, Z. (2009) Analysis on the Mechanism of Reverse Spillover Effect of Chinese Enterprise Technology Acquisition FDI. Shandong Economy, 5, 64-69.

[14] Guo, F. and Huang, Y. (2012) The Research on the Transmission Mechanism of OFDI Reverse Technology Spillover Effect from the Perspective of Global Value Chain-HUAWEI Technology Co. Ltd. as an Example. Journal of Management, 3.

[15] Bitzer, J. and Kerekes, M. (2008) Does Foreign Direct Investment Transfer Technology across Borders? New Evidence. Economics Letters, 100, 355-358. https://doi.org/10.1016/j.econlet.2008.02.029

[16] Herzer, D. (2010) The Long-Run Relationship between Outward FDI and Total Factor Productivity: Evidence for Developing Countries.

[17] Wang, Y. and Liu, S. (2008) An Empirical Study of the International Technology Spillover Channels. The Journal of Quantitative \& Technical Economics, 4, 153-161. 